\title{
Brain Metastasis and Renal Cell Carcinoma: Prognostic Scores Assessment in the Era of Targeted Therapies
}

\author{
ZIAD EL ALI ${ }^{1 *}$, SYLVIE ROTTEY $^{2}$, PHILIPPE BARTHELEMY ${ }^{3}$, NURIA KOTECKI ${ }^{1,4}$, RUBEN VAN PAEMEL $^{2}$, \\ DANIEL DEVRIENT ${ }^{5}$, AHMAD AWADA ${ }^{1}$, THIERRY GIL ${ }^{1}$, DIANE PANNIER ${ }^{4}$, THOMAS RYCKEWAERT ${ }^{4}$, \\ WAISSI WAISSE ${ }^{6}$, JEAN-BAPTISTE CLAVIER ${ }^{6}$, NICOLAS PENEL ${ }^{4}$ and TIJL VERMASSEN ${ }^{2}$ \\ ${ }^{1}$ Medical Oncology Clinic, Institut Jules Bordet, Université Libre de Bruxelles, Brussels, Belgium; \\ ${ }^{2}$ Department of Medical Oncology, Ghent University Hospital, Ghent, Belgium; \\ ${ }^{3}$ Medical Oncology Department, Hôpitaux Universitaires de Strasbourg, Strasbourg, France; \\ ${ }^{4}$ Department of General Oncology, Centre Oscar Lambret, Lille, France; \\ ${ }^{5}$ Radiotherapy Department, Jules Bordet Institute, Brussels, Belgium; \\ ${ }^{6}$ Radiation Oncology Department, Comprehensive Cancer Center Paul Strauss, Strasbourg, France
}

\begin{abstract}
Aim: This study aimed at exploring several brain metastatic prognostic scores in patients with renal cell carcinoma. Patients and Methods: We retrospectively analyzed data of 93 metastatic renal cell carcinoma patients who were diagnosed with brain metastases between October 2005 and July 2016 who received targeted therapy. Potential prognostic factors (RTOG RPA, BS-BM, and a newly developed score CERENAL) were analyzed. Results: A total of 75 patients received targeted therapy. All scores showed prognostic value in progression-free survival after first-line treatment with CERENAL being the sole independent prognostic factor associated with improved duration of first-line treatment. Both RTOG RPA and CERENAL were potential prognosticators for overall survival, whereas only the CERENAL score was associated with prolonged disease-specific survival. Conclusion: Several prognostic scores can be useful to predict survival of patients with brain metastases from renal cancer, especially the newly developed CERENAL score.
\end{abstract}

Renal cell carcinoma (RCC) accounts for $2.4 \%$ of all malignancies diagnosed worldwide with 337,800 estimated new cases globally and 115,200 new patients in Europe in 2012 (1-3). At primary diagnosis, approximately $25 \%$ of patients are diagnosed with advanced RCC (4).

In case of metastatic disease, median overall survival (OS) is 18.8 months, with 5-year disease-specific survival rates of

Correspondence to: Ziad El Ali, Medical Oncology Clinic, Institut Jules Bordet, Université Libre de Bruxelles, 121-125 Boulevard de Waterloo, Brussels, Belgium. Tel: +32 25413111, e-mail: ziad.elali@bordet.be

Key Words: Brain metastasis, renal cell carcinoma, survival, prognostic factors.
$32 \%, 19.5 \%$ and $0 \%$ found for patients with low-, intermediate- and high-risk respectively $(1,5)$. However, recent data from trials with immunotherapy in metastatic RCC showed 2-year OS rates up to 70\% (5).

Brain metastases occur in 10\% of metastatic RCC patients (6). Local treatment options such as surgery or radiotherapy are considered the standard of care to treat brain metastases. However, as brain metastases tend to be relatively resistant to whole-brain radiation therapy, use of stereotactic radiosurgery seems to result in a satisfactory control of brain metastases with only a limited survival benefit $(7,8)$. Nevertheless, overall prognosis remains poor with nearly all patients succumbing to the disease within 2 years of brain metastasis diagnosis $(8,9)$.

Several prognostic scores for brain metastases have been reported to determine the prognostic outcome of patients following brain surgery or radiotherapy, such as the Radiation Therapy Oncology Group Recursive Partitioning Analysis (RTOG RPA), the Score Index for Radiosurgery and the Basic Score for Brain Metastases (BS-BM) (10-12). However, these scores were developed and validated in studies with various tumor types, usually with none or only one small RCC subgroup.

Therefore, the goal of this retrospective study was to validate the brain metastasis prognostic scores RTOG-RPA and BS-BM in patients with renal cell cancer treated with targeted therapies. Next, we aimed at developing a potential new tool named CERENAL score for this population and evaluate the prognostic potential for PFS and OS.

\section{Patients and Methods}

Patient selection. We retrospectively identified metastatic RCC patients who were diagnosed with or developed brain metastases during the course of their disease in four international cancer centers 
between October 2005 and July 2016. Patient data were retrieved from the electronic patient files. All patients with brain metastases treated with targeted therapies, including tyrosine kinase inhibitors and mTOR inhibitors, were included. This study was approved by the Ethics Committee of all participating centers. Informed consent was given by all participants. The study was conducted according to the principles of the Helsinki declaration.

Prognostic factors. Brain metastasis prognostic scores were determined as described in literature. Patients were distributed among RTOG RPA classes I, II or III using age, Karnofsky performance status (KPS) and presence of extracranial metastases at brain metastasis diagnosis (10). Next, the BS-BM was determined using KPS, management of systemic disease and presence of extracranial metastases at brain metastasis diagnosis. Up to one point was attributed per prognostic factor with a final BS-BM ranging between 0 and 3 (11). Due to limited data in the patient data files on the volume of the brain lesions, the Score Index for Radiosurgery (12) could not be calculated.

As the majority of these scores were developed and validated in populations with mainly lung cancer, breast cancer, or malignant melanoma, a novel brain metastasis prognostic score was devised, namely CERENAL, based on the prognostic parameters used for the RTOG RPA and the BS-BM and findings in literature showing that a low number of intracranial metastases and SRS may predict a substantial survival benefit for metastatic RCC patients $(8,13)$. In this score, 1 point was attributed for each negative prognostic factor for a total score ranging between 0 and 6 points. All three brain metastasis prognostic scores are described in Table I. All prognostic scores were then dichotomized for survival analysis based on median numbers for each prognostic variable. Patients were subdivided as RTOG RPA class I-II versus RTOG RPA class III. For BS-BM and CERENAL, cut-off was taken at $\leq 2$ and $\leq 4$, respectively. Insufficient retrospective data was available to determine MSKCC or Heng criteria.

Statistical analysis. Spearman's rank correlation coefficient @ was assessed between prognostic scores. The overall percentage agreement was calculated pairwise for comparison between all dichotomized prognostic scores. Each prognostic score was calibrated for progression-free survival (PFS, time from treatment initiation until radiographic progression or discontinuation due to adverse events) and OS (time from brain metastasis diagnosis until day of death or last follow-up) by means of a logistic regression model (Hosmer-Lemeshow test). Small $\chi^{2} /$ larger $p$-values indicate a good model fit.

The hazard ratio (HR) of each prognostic score on first-line PFS, second-line PFS, OS and disease-specific survival (DSS) was determined by a 2-sided log-rank (Mantel-Cox) test. Patients that were lost to follow-up were censored in the survival analysis. Survival curves were plotted using the Kaplan-Meier method. Comparison of survival rates between all dichotomized prognostic scores for six-months first-line PFS, six-months second-line PFS, six-months OS, one-year OS, six-months DSS, and one-year DSS was performed using decision curve analysis (14). The covariate effect of the survival risk factors (reaching $p$-value $<0.05$ on univariate test), was determined via Cox proportional hazard model (backward method). Missing values were not included in the analyses. $p$-Values $<0.05$ were considered statistically significant. Analyses were performed with MedCalc Statistical Software v17.4
Table I. Calculation of brain metastatic prognostic scores.

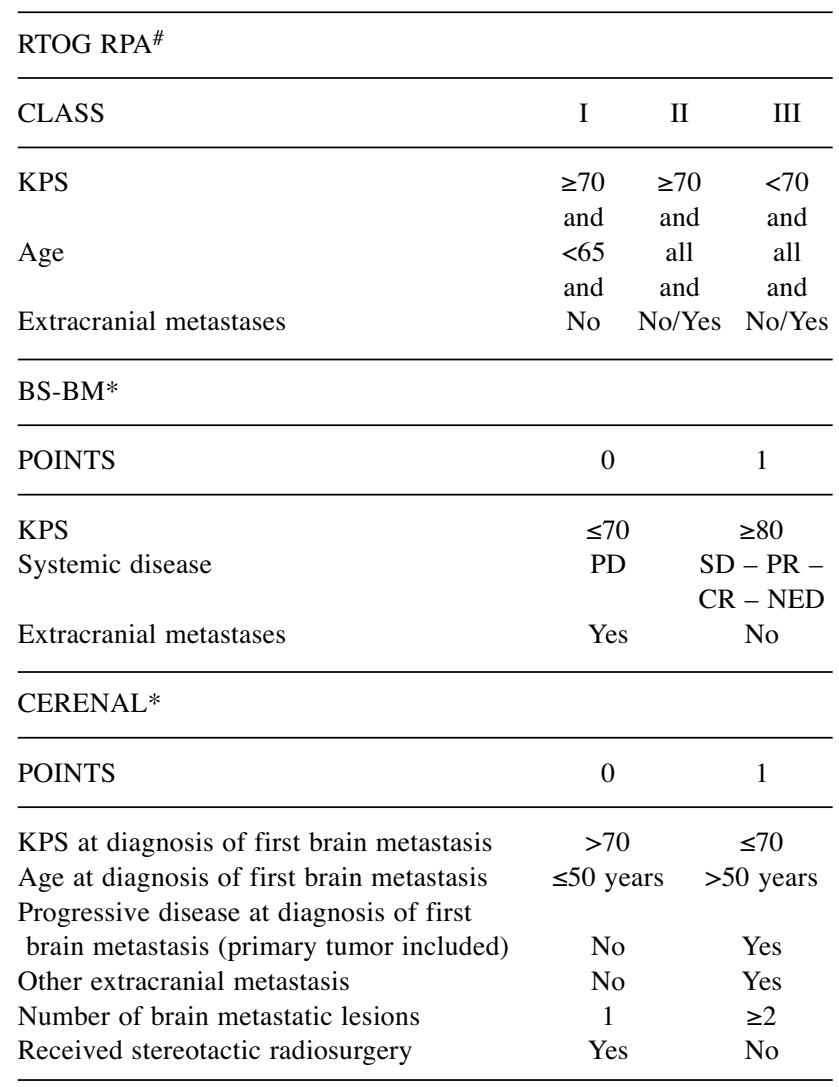

\#Patients are subdivided in class according to the combination of all three criteria. *Final score is obtained by sum of all individual points. KPS, Karnofsky performance status.

(MedCalc Software, Ostend, Belgium); SPSS v23.0 (IBM corporation, Armonk, NY, USA), GraphPad Prism v4.7 (GraphPad Software Inc., La Jolla, CA, USA) and RStudio v3.5.1 (RStudio, Boston, MA, USA).

\section{Results}

Patient characteristics and prognostic scores. Out of 93 RCC patients who were diagnosed with brain metastasis, eighteen patients did not receive targeted therapy and were excluded from all analyses. An overview of the clinical characteristics as well as a descriptive analysis concerning the diagnosis and specific treatment of brain metastases in the intention-to-treat cohort (75 cases) is given in Tables II and III, respectively.

Patient distribution among brain metastasis prognostic scores is shown in Table IV. Prognostic scores were comparable to each other. A moderate rank correlation was found between RTOG RPA and BS-BM $(\mathrm{Q}=-0.700, p<0.0001)$ and between CERENAL and BS-BM $(\mathrm{Q}=-0.702, p<0.0001)$ whereas a fair rank correlation was found between RTOG RPA and CERENAL $(\mathrm{Q}=0.533, p<0.0001)$. Dichotomization of the 
Table II. Clinical characteristics in the intention-to-treat cohort ( $n=75)$.

\begin{tabular}{|c|c|}
\hline \multicolumn{2}{|l|}{ Gender } \\
\hline Male & $57(76)$ \\
\hline Female & $18(24)$ \\
\hline Median age, years & $55(28-82)$ \\
\hline \multicolumn{2}{|l|}{ Histology } \\
\hline Clear-cell & $66(88)$ \\
\hline Papillary & $2(3)$ \\
\hline Chromophobe & $2(3)$ \\
\hline Not determined & $5(7)$ \\
\hline \multicolumn{2}{|c|}{ Sarcomatoid component } \\
\hline Yes & $8(11)$ \\
\hline No & $28(37)$ \\
\hline Not determined & $39(52)$ \\
\hline \multicolumn{2}{|l|}{ Fuhrmann grade } \\
\hline I-II & $8(11)$ \\
\hline III & $27(36)$ \\
\hline IV & $9(12)$ \\
\hline Unknown & $31(41)$ \\
\hline \multicolumn{2}{|l|}{ Nephrectomy } \\
\hline Yes & $57(76)$ \\
\hline No & $18(24)$ \\
\hline \multicolumn{2}{|l|}{ IMDC risk group } \\
\hline Good & $12(16)$ \\
\hline Intermediate & $28(37)$ \\
\hline Poor & $16(21)$ \\
\hline Unknown & $19(25)$ \\
\hline \multicolumn{2}{|l|}{ Site of metastasis } \\
\hline Lungs & $38(51)$ \\
\hline Liver & $14(19)$ \\
\hline Bones & $15(20)$ \\
\hline Adrenal glands & $16(21)$ \\
\hline Lymph nodes & $28(37)$ \\
\hline Other & $13(17)$ \\
\hline
\end{tabular}

Data given are number (percentage) except for age at RCC diagnosis: median (range).

prognostic scores showed moderate overall percentage agreement $(68 \%, 79 \%, 68 \%)$ for RTOG RPA versus BS-BM, CERENAL versus BS-BM, and RTOG RPA versus CERENAL, respectively. RTOG RPA, BS-BM and CERENAL showed excellent model fit for first-line PFS $\left(\chi^{2}=9.18 \mathrm{E}-9\right.$, $p=0.9999 ; \chi^{2}=6.40 \mathrm{E}-9, p=1.0000 ;$ and $\chi^{2}=4.57 \mathrm{E}-9, p=1.0000$, respectively) and OS $\left(\chi^{2}=5.74 \mathrm{E}-9, p=1.0000 ; \chi^{2}=5.74 \mathrm{E}-9\right.$, $p=1.0000$; and $\chi^{2}=7.86 \mathrm{E}-9, p=1.0000$, respectively).

PFS after first- and second-line targeted therapy. A total of $36 / 75$ patients $(48 \%)$ were diagnosed with brain metastases at first-line treatment initiation. Median follow-up time since first-line therapy until death or last follow-up was 54.7 months (42.8-66.5). An overview of administered therapies with median duration of first-line therapy and PFS per therapy are given in Table $\mathrm{V}$.

All prognostic scores showed significance in PFS after first-line targeted therapy. Patients classified as RTOG RPA class I/II showed a prolonged PFS in comparison with RTOG
Table III. Brain metastases characteristics at brain metastasis diagnosis in the intention-to-treat cohort $(n=75)$.

\begin{tabular}{|c|c|}
\hline $\begin{array}{l}\text { Time between diagnosis of primary } \\
\text { tumor and diagnosis of brain metastasis (months) }\end{array}$ & $15(0-381)$ \\
\hline \multicolumn{2}{|l|}{ Brain metastasis at diagnosis } \\
\hline Yes & $15(20)$ \\
\hline No & $60(80)$ \\
\hline \multicolumn{2}{|l|}{$\begin{array}{l}\text { Other metastatic sites involved } \\
\text { at brain metastasis diagnosis }\end{array}$} \\
\hline No sites & $2(3)$ \\
\hline Lungs & $62(83)$ \\
\hline Lymph nodes & $41(55)$ \\
\hline Liver & $17(23)$ \\
\hline Bones & $29(39)$ \\
\hline Adrenal gland & $14(19)$ \\
\hline Other & $20(27)$ \\
\hline \multicolumn{2}{|l|}{ Localization of brain metastasis } \\
\hline Supratentorial & $36(48)$ \\
\hline Infratentorial & $2(3)$ \\
\hline Both & $12(16)$ \\
\hline Unknown & $25(33)$ \\
\hline \multicolumn{2}{|l|}{ Number of brain metastases } \\
\hline 1 & $38(51)$ \\
\hline 2 & $13(17)$ \\
\hline $3+$ & $23(31)$ \\
\hline Not determined & $1(1)$ \\
\hline \multicolumn{2}{|l|}{ Neurological symptoms } \\
\hline Yes & $47(63)$ \\
\hline No & $28(37)$ \\
\hline \multicolumn{2}{|l|}{$\begin{array}{l}\text { Received first-line targeted therapy } \\
\text { before brain metastasis diagnosis }\end{array}$} \\
\hline Yes & $39(52)$ \\
\hline No & $36(48)$ \\
\hline \multicolumn{2}{|l|}{ Additional therapy for brain metastases } \\
\hline No additional therapy & $8(11)$ \\
\hline WBRT alone & $27(36)$ \\
\hline SRS alone & $12(16)$ \\
\hline Surgery + WBRT & $17(23)$ \\
\hline Surgery + SRS & $3(4)$ \\
\hline WBRT + SRS & $3(4)$ \\
\hline Surgery + WBRT + SRS & $5(7)$ \\
\hline
\end{tabular}

Data given are number (percentage) except for time between primary tumor and brain metastasis: median (range). SRS, Stereotactic radiosurgery; WBRT, whole-brain radiotherapy.

RPA class III [median $\mathrm{PFS}=10.3$ versus 3.6 months; $\mathrm{HR}=0.28(0.02-0.3), p=0.0013]$. A similar outcome was found for the BS-BM score. Having a BS-BM score of 2 or 3 resulted in a $56 \%$ reduction in risk of progression $[\mathrm{HR}=0.44(0.17-0.82), p=0.0140]$ with median PFS of 11.9 months compared with 5.6 months for BS-BM score lower than 2. Patients having a CERENAL score lower than 4 also had a longer median PFS (11.9 versus 4.1 months) resulting in a $64 \%$ reduction in risk of progression $[\mathrm{HR}=0.36(0.09$ $0.57), p=0.0015$; Figure $1 \mathrm{~A}-\mathrm{C}]$. Decision curve analysis for six-months PFS showed that the CERENAL score achieved highest net benefit between the 0.2 and 0.4 risk threshold, 
Table IV. Brain metastasis prognostic scores at brain metastasis diagnosis in the intention-to-treat cohort $(n=75)$.

\begin{tabular}{|c|c|c|c|c|c|c|}
\hline Prognostic scores & $\mathrm{n}$ & $(\%)$ & $\operatorname{mOS}(95 \% \mathrm{CI})$ & $p$-Value & $\operatorname{mDSS}(95 \% \mathrm{CI})$ & $p$-Value \\
\hline \multicolumn{7}{|l|}{ RTOG RPA } \\
\hline I & 1 & (1) & $35.6(-)$ & \multirow[t]{3}{*}{0.0001} & $35.6(-)$ & \multirow[t]{3}{*}{0.0007} \\
\hline II & 49 & (65) & $19.3(10.2-30.5)$ & & $16.8(10.2-32.5)$ & \\
\hline III & 25 & (33) & $6.0(3.4-9.1)$ & & $6.0(2.6-11.5)$ & \\
\hline \multicolumn{7}{|l|}{ BS-BM } \\
\hline 0 & 13 & (17) & $5.6(2.2-10.5)$ & \multirow[t]{4}{*}{0.0001} & $5.6(1.0-12.2)$ & \multirow[t]{4}{*}{0.0015} \\
\hline 1 & 36 & (48) & $9.1(5.0-14.9)$ & & $10.2(5.0-15.2)$ & \\
\hline 2 & 25 & (33) & $30.5(19.3-40.6)$ & & $22.6(14.2-67.6)$ & \\
\hline 3 & 1 & (1) & $35.6(-)$ & & $35.6(-)$ & \\
\hline \multicolumn{7}{|l|}{ CERENAL } \\
\hline 1 & 2 & (3) & $58.9(-)$ & \multirow[t]{6}{*}{$<0.0001$} & $35.6(-)$ & \multirow[t]{6}{*}{$<0.0001$} \\
\hline 2 & 11 & (15) & $39.3(30.5-70.5)$ & & $67.6(32.5-70.6)$ & \\
\hline 3 & 16 & (21) & $19.3(9.2-22.6)$ & & $19.3(9.2-23.8)$ & \\
\hline 4 & 21 & (28) & $6.3(5.0-13.2)$ & & $6.3(3.1-13.2)$ & \\
\hline 5 & 21 & (28) & $10.9(4.4-15.2)$ & & $11.5(4.7-15.2)$ & \\
\hline 6 & 4 & (5) & $1.0(1.0-10.5)$ & & $1.0(1.0-2.3)$ & \\
\hline
\end{tabular}

Data given are number (percentage). mOS and mDSS are given in months. 95\%CI, 95\% Confidence interval; BS-BM, basic score for brain metastases; mDSS, median disease-specific survival; mOS, median overall survival; RTOG RPA, radiation therapy oncology group recursive partitioning analysis.

Table V. Targeted therapies administered in patients diagnosed with brain metastasis and survival outcome.

\begin{tabular}{lccccc}
\hline Therapy & $\mathrm{n}$ & $(\%)$ & $\mathrm{mPFS}(95 \% \mathrm{CI})$ & $\mathrm{mOS}(95 \% \mathrm{CI})$ & $\mathrm{mDSS}(95 \% \mathrm{CI})$ \\
\hline Intention-to-treat cohort* & 75 & $(100)$ & $10.1(7.1-11.4)$ & $11.5(8.8-16.8)$ & $12.2(8.5-16.8)$ \\
First-line therapy & 36 & $(100)$ & $10.1(4.1-11.9)$ & $16.8(12.2-32.9)$ & $15.2(11.5-39.3)$ \\
Sunitinib & 21 & $(58)$ & $10.3(7.8-14.2)$ & $20.4(4.2-67.6)$ & $16.8(12.2-70.5)$ \\
Pazopanib & 3 & $(8)$ & $2.6(2.6-3.6)$ & $10.5(3.9-13.9)$ & $13.9(-)$ \\
Sorafenib & 5 & $(14)$ & $11.2(10.1-11.9)$ & $39.3(19.3-58.9)$ & $22.3(19.3-40.6)$ \\
Everolimus & 2 & $(6)$ & $2.6(2.6-5.6)$ & $10.9(10.9-11.5)$ & $10.9(10.9-11.5)$ \\
Temsirolimus & 5 & $(14)$ & $2.2(1.0-23.4)$ & $6.0(2.3-23.8)$ & $6.0(2.3-23.8)$ \\
Duration first-line therapy (months) & 9.6 & $(1.0-55.8)$ & & & \\
Number of patients stopped for AE & 5 & $(14)$ & & & \\
Second-line therapy+ & 29 & $(100)$ & $5.0(3.1-6.5)$ & $32.5(15.2-52.7)$ & $23.8(14.9-40.6)$ \\
Sunitinib & 4 & $(14)$ & $5.1(0.4-19.7)$ & $39.3(23.8-58.9)$ & $39.3(23.8-40.6)$ \\
Pazopanib & 1 & $(3)$ & $2.6(-)$ & $13.9(-)$ & $13.9(-)$ \\
Sorafenib & 5 & $(17)$ & $2.8(1.4-5.0)$ & $11.5(10.9-70.6)$ & $11.5(10.9-70.6)$ \\
Everolimus & 12 & $(41)$ & $4.1(2.1-37.5)$ & $32.5(16.8-54.0)$ & $22.4(14.9-54.0)$ \\
Axitinib & 4 & $(14)$ & $3.5(3.1-6.5)$ & $10.5(8.5-15.2)$ & $15.2(8.5-\mathrm{NR})$ \\
Temsirolimus & 2 & $(7)$ & $7.0(-)$ & $70.5(70.5-70.6)$ & $70.5(70.5-70.6)$ \\
Interferon- $\gamma$ & 1 & $(3)$ & $5.1(-)$ & $8.8(-)$ & $8.8(-)$ \\
Duration second-line therapy (months) & 3.5 & $(0.0-37.5)$ & & & \\
Number of patients stopped for AE & 6 & $(21)$ & & & \\
\hline
\end{tabular}

Data given are number (percentage) except for duration of therapy: median (range). mPFS, mOS and mDSS are given in months. *mPFS in intentionto-treat cohort is independent of prior targeted therapy before brain metastasis diagnosis. ${ }^{\S} \mathrm{A}$ total of 36 patients were diagnosed with brain metastases before first-line therapy was initiated. ${ }^{+}$Out of the 36 patients with brain metastases who were treated in first-line, 21 started second-line therapy together with eight patients diagnosed with brain metastases during first-line therapy. 95\% CI, 95\% Confidence interval; mDSS, median diseasespecific survival; mOS, median overall survival; mPFS, median progression-free survival.

whereas RTOG RPA indicated the highest net benefit above the 0.4 risk threshold. BS-BM showed the lowest net benefit for every risk threshold (Figure 2A). A multivariate analysis proved that the CERENAL score was the sole independent prognostic factor associated with an improved PFS from first-line therapy ( $p=0.0029$, Table VI, First-line PFS).
Twenty-one out of 36 patients diagnosed with brain metastases at start of first-line therapy together with 8 patients newly diagnosed with brain metastases during their first-line therapy received second-line targeted therapy. An overview of administered therapies and median duration of second-line therapy are given in Table V. 
In comparison to first-line therapy, no prognostic value was found for RTOG RPA [HR RTOG RPA class I/II $=0.62(0.18$ -

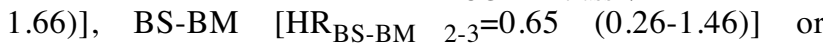
CERENAL $\left[\mathrm{HR}_{\text {CERENAL 1-3 }}=0.76(0.33-1.75)\right]$. This is also shown on the decision curves for six-months PFS with only marginal net benefit found for CERENAL between the 0.55 and 0.75 risk threshold (Figure $2 \mathrm{~B}$ ).

OS and DSS. Of all patients, 63/75 (84\%) were deceased and 9/75 (12\%) were lost-to-follow-up at time of OS analysis. Median follow-up time since diagnosis of brain metastases until death or last follow-up was 62.1 months (52.6-71.5). Median OS per first- and second-line therapy are given in Table V.

Univariate analysis confirmed the prognostic value of the different prognostic scores. Patients classified as RTOG RPA class I/II showed a median OS of 20.4 versus 6.0 months for patients classified as RTOG RPA class III [HR=0.36 (0.11$0.44), p<0.0001]$. Moreover, patients with BS-BM 2-3 had an improved outcome compared with patients with BS-BM 0-1 [median OS $=30.5$ versus 6.6 months; $\mathrm{HR}=0.38(0.17-0.55)$, $p<0.0001]$. Median OS was significantly longer in patients with CERENAL 1-3 versus CERENAL 4-6 (30.5 versus 6.3 months) with a $59 \%$ reduction in risk of death $[\mathrm{HR}=0.37$ (0.17$0.51), p<0.0001]$ (Figure 3A-C). Patients receiving local therapy for brain metastases had an improved median OS versus those who did not [13.9 versus 5.3 months; $\mathrm{HR}=0.44$ (0.09-0.90), $p=0.0324]$. Highest net benefit for six-months OS was found for CERENAL for risk thresholds up to 0.4 whereas RTOG RPA proved more beneficial between the 0.4 and 0.5 risk threshold (Figure 2C). At one-year OS, BS-BM and CERENAL proved to be comparable on decision curve analysis with highest net benefit between the 0.3 and 0.55 risk threshold, although RTOG RPA is more beneficial between the 0.55 and 0.8 risk threshold (Figure 2D). This was deflected in the multivariate analysis which suggested that RTOG RPA $(p=0.0428)$ and CERENAL score $(p=0.0063)$ are independent prognostic factors (Table VI, OS).

Of all deceased patients, 49/63 (78\%) died from their disease. Comparable to OS, all prognostic scores were significant for DSS. Median DSS for first- and second-line therapy are given in Table V. Having a prognostic favorable score resulted in a significant reduction in risk of death of $63 \%, 61 \%$ and $62 \%$ for RTOG RPA, BS-BM and CERENAL, respectively ( $p=0.0002, p=0.0007$ and $p=0.0003$; Figure $4 \mathrm{~A}$ C). Likewise, patients who had additional brain metastatic therapy lived longer in comparison to patients who did not undergo local therapy [13.9 vs. 5.0 months; HR=0.42(0.08$0.94), p=0.0390]$. Decision curves for six-months DSS and one-year DSS were similar with those observed for sixmonths OS and one-year OS (Figure 2E and F). However, in contrast to OS, only CERENAL $(p=0.0005)$ was an independent prognostic factor associated with DSS in the multivariate analysis (Table VI, DSS).
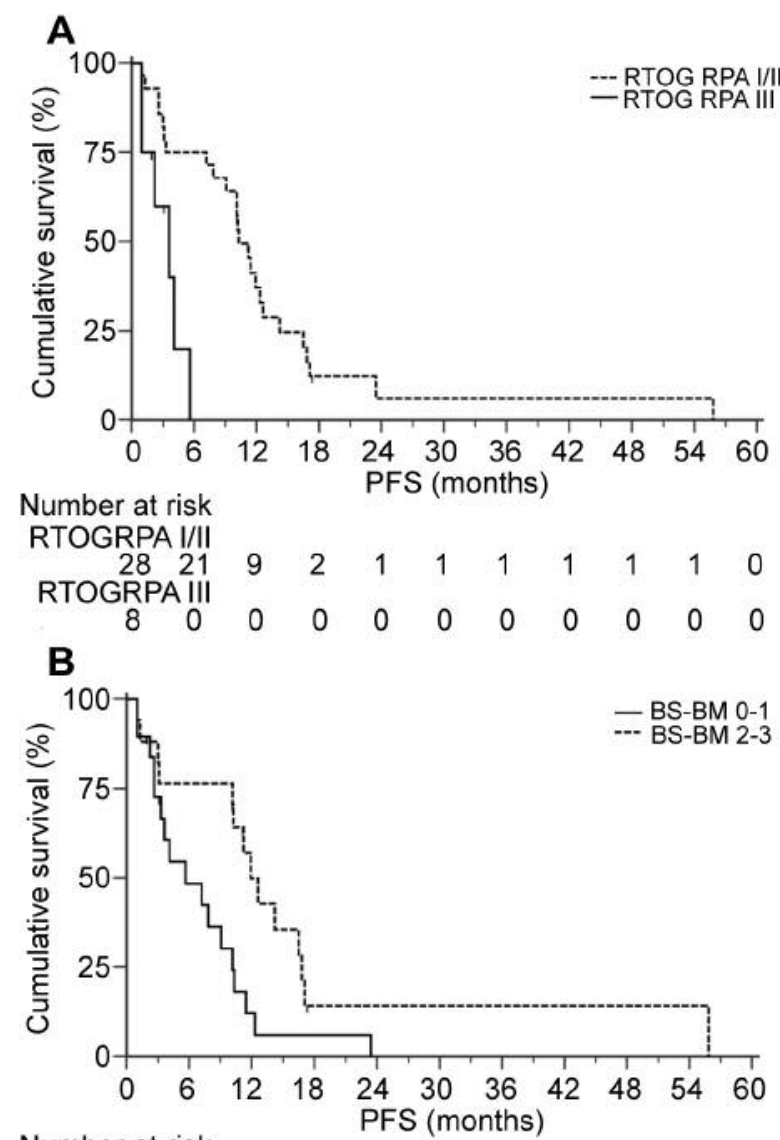

Number at risk

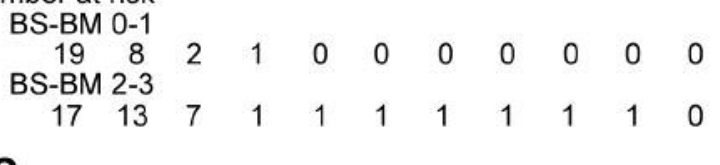

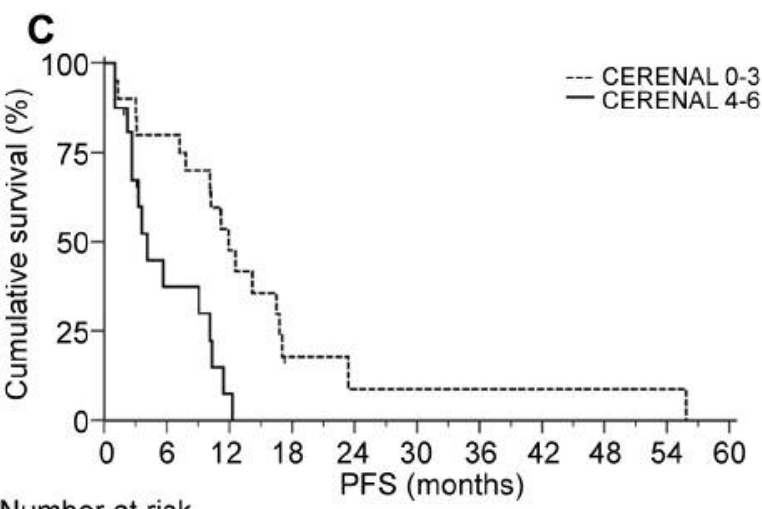

Number at risk

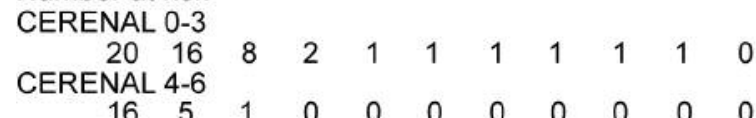

Figure 1. Kaplan-Meier first-line progression-free survival curves for brain metastasis prognostic scores. Y-axis depicts cumulative survival (\%), $X$-axis depicts survival time in months. Survival curves are demonstrated for (A) RTOG RPA ( $p=0.0013)$, (B) BS-BM $(p=0.0140)$, (C) CERENAL ( $p=0.0015)$. BS-BM, Basic score for brain metastases; $P F S$, progression-free survival; RTOG RPA, radiation therapy oncology group recursive partitioning analysis. 

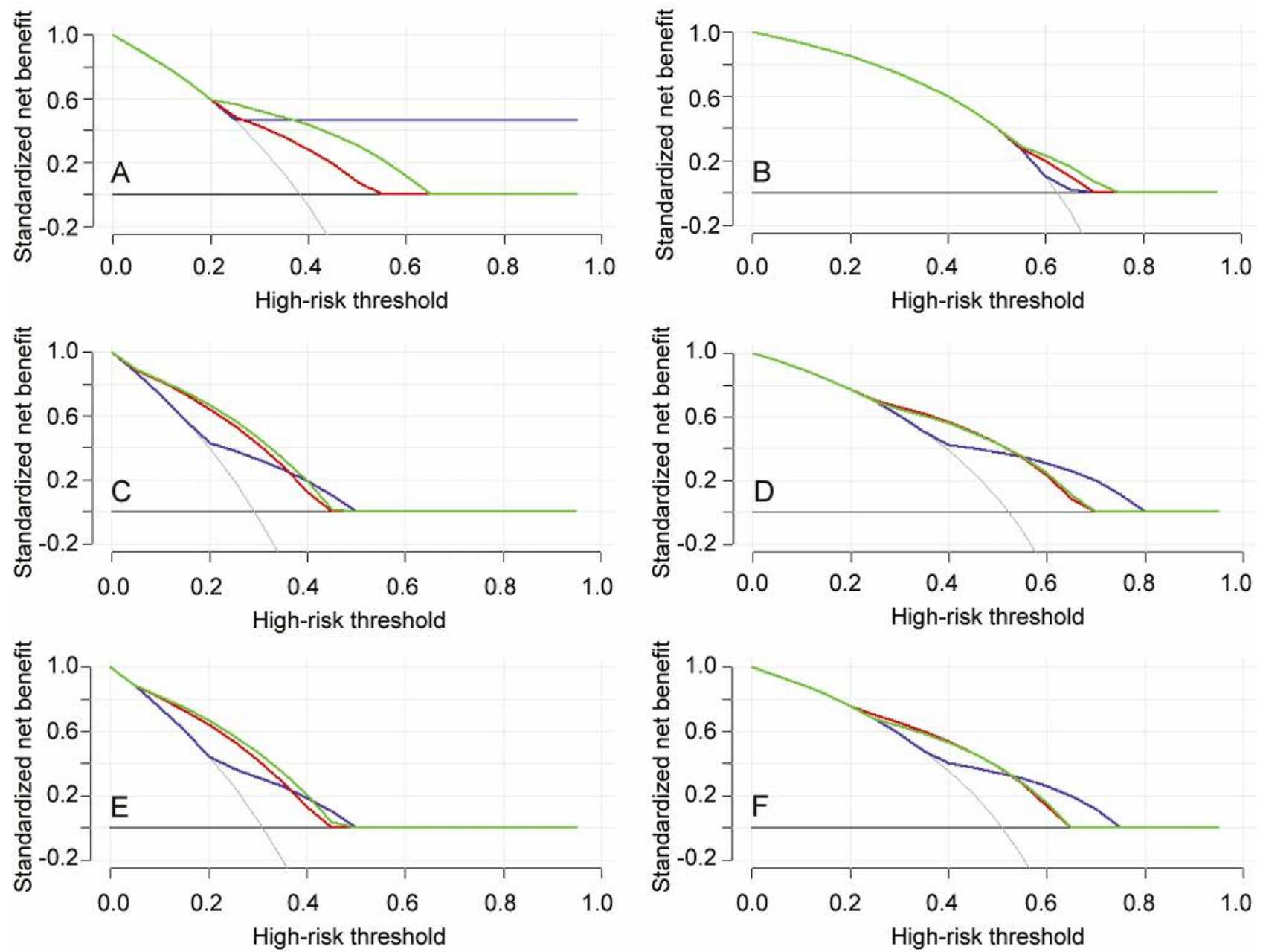

Figure 2. Decision curve analysis for brain metastasis prognostic scores. Y-axis depicts the standardized net benefit, $X$-axis depicts the risk thresholds. Decision curves (RTOG RPA=blue line, BS-BM=red line, CERENAL=green line) are demonstrated for (A) six-months first-line PFS, (B) six-months second-line PFS, (C) six-months OS, (D) one-year OS, (E) six-months DSS, (F) one-year DSS. BS-BM, Basic score for brain metastases; PFS, progression-free survival; RTOG RPA, radiation therapy oncology group recursive partitioning analysis.

\section{Discussion}

Patients with RCC diagnosed with brain metastases have a poor survival. Several brain metastatic prognostic scores have been reported in the literature over the last decade. Data in a metastatic RCC setting are, however, scanty. We, therefore, retrospectively determined the prognostic value of several prognostic scores, developed for brain metastases in solid tumors, in a cohort of 75 patients with brain metastatic RCC receiving targeted agents (tyrosine kinase inhibitors or mTOR inhibitors). Here, we evaluated two already described prognostic scores, RTOG RPA and BS-BM $(10,11)$, as well as a de novo composed score CERENAL.

In our study population, $75 \%$ of patients were diagnosed with metastatic disease at primary RCC diagnosis which is considerable higher compared to other reported data (4). This could be explained by the fact that the brain is rarely the only metastatic site in RCC. Nearly $20 \%$ of our patients presented with brain metastases at primary tumor diagnosis. This is comparable to the extent registered in other RCC studies $(7-26.8 \%)$. It is notable that the time from primary RCC diagnosis to diagnosis of brain metastases is clearly shorter in our study (15 months) $(15,16)$.

In addition to the previously described prognostic scores RTOG RPA and BS-BM, we assessed the novel score named CERENAL in which points were attributed according to risk factors described in RTOG RPA and BS-BM. Furthermore, the number of brain metastatic lesions was also included in the CERENAL score since Ferrel et al. (13) reported an improved OS in RCC patients with a low number of intracranial metastases. Since SRS therapy has been shown to have a positive effect on the survival outcome of brain 
Table VI. Multivariate survival analysis.

\begin{tabular}{|c|c|c|}
\hline Parameter & HR $(95 \% \mathrm{CI})$ & $p$-Value \\
\hline \multicolumn{3}{|c|}{ First-line PFS } \\
\hline \multicolumn{3}{|c|}{ RTOG RPA } \\
\hline $\mathrm{I} / \mathrm{II}$ & 1 & \\
\hline III & $2.76(0.83-9.22)$ & 0.0989 \\
\hline \multicolumn{3}{|l|}{ BS-BM } \\
\hline $0-1$ & 1 & \\
\hline $2-3$ & $0.86(0.23-3.15)$ & 0.8186 \\
\hline \multicolumn{3}{|c|}{ CERENAL } \\
\hline $1-3$ & 1 & \\
\hline $4-6$ & $3.59(1.55-8.34)$ & 0.0029 \\
\hline \multicolumn{3}{|l|}{ OS } \\
\hline \multicolumn{3}{|c|}{ RTOG RPA } \\
\hline $\mathrm{I} / \mathrm{II}$ & 1 & \\
\hline III & $1.95(1.02-3.72)$ & 0.0428 \\
\hline \multicolumn{3}{|l|}{ BS-BM } \\
\hline $0-1$ & 1 & \\
\hline $2-3$ & $0.65(0.21-1.98)$ & 0.4479 \\
\hline \multicolumn{3}{|c|}{ CERENAL } \\
\hline $1-3$ & 1 & \\
\hline $4-6$ & $2.56(1.30-5.03)$ & 0.0063 \\
\hline \multicolumn{3}{|c|}{ Local therapy for brain metastases } \\
\hline No & 1 & \\
\hline Yes & $0.78(0.34-1.79)$ & 0.5575 \\
\hline \multicolumn{3}{|c|}{ DSS } \\
\hline \multicolumn{3}{|c|}{ RTOG RPA } \\
\hline $\mathrm{I} / \mathrm{II}$ & 1 & \\
\hline III & $1.90(0.93-3.87)$ & 0.0785 \\
\hline \multicolumn{3}{|l|}{ BS-BM } \\
\hline $0-1$ & 1 & \\
\hline $2-3$ & $0.66(0.19-2.32)$ & 0.5174 \\
\hline \multicolumn{3}{|c|}{ CERENAL } \\
\hline $1-3$ & 1 & \\
\hline $4-6$ & $3.34(1.70-6.56)$ & 0.0005 \\
\hline \multicolumn{3}{|c|}{ Local therapy for brain metastases } \\
\hline No & 1 & \\
\hline Yes & $0.67(0.27-1.66)$ & 0.6698 \\
\hline
\end{tabular}

Multivariate HRs were calculated via a Cox proportional-hazards regression model. 95\% CI, 95\% Confidence interval; BS-BM, basic score for brain metastases; DSS, disease-specific survival; OS, overall survival; PFS, progression-free survival; RTOG RPA, radiation therapy oncology group recursive partitioning analysis.

metastatic RCC patients (8), it was decided to include SRS in the CERENAL score. However, several trials have reported no difference in outcome between SRS and local therapies for brain metastases (17-20). Due to the fact that several mutual risk factors were used, all prognostic scores were comparable to each other with the highest level of agreement noticed between CERENAL and BS-BM. In addition, we confirmed the robustness of all prognostic scores used in our study.

In the present study, median OS was between 11.5 months (intention-to-treat group) and 16.8 months (brain metastases before first-line targeted therapy) which is similar to the survival data from other studies in RCC patients with brain metastases $(9,15,16,21)$. Compared to the OS data from large phase III trials, in which patients with brain metastatic disease were excluded, OS is significantly shorter (22-30). This difference, however, was not the result of a possible decrease in first-line PFS. Median first-line PFS was 10.1 months with the majority of patients receiving sunitinib as first-line therapy. This is only marginally shorter than the survival data from previously reported phase III trials COMPARZ and RECORD$3(25,29)$, suggesting that having brain metastases seems to have only little to no impact on first-line PFS. This has already been hypothesized by Kusuda et al. (31) who reported that sunitinib might harbor some effect on brain metastases. Next, second-line PFS was only 5.0 months which is in accordance with second-line PFS in large phase III trials (AXIS, RECORD-1) with tyrosine kinase inhibitors $(23,25,28,30)$ and the mTOR inhibitor everolimus (27).

Based on these data it is clear that RCC patients with brain metastases have a poor prognosis. Use of brain metastatic prognostic scores in these patients can, therefore, be useful to determine which patients would benefit from prolonged therapy. It has been previously described for melanoma, lung and breast cancer that the RTOG RPA and the BS-BM result in significantly different survival curves (19, 32-34). To our knowledge, such an extensive survival comparison has not yet been made for brain metastatic RCC.

RTOG RPA and BS-BM developed in other malignancies were significantly associated in our study with both OS and DSS. Moreover, our newly constructed CERENAL score was also able to distinguish patients with good prognosis from those with poor prognosis at the predefined cut-off value. Thus, any type of local therapy for brain metastases significantly prolonged OS and DSS. Consequent multivariate analysis revealed RTOG RPA and CERENAL as independent prognostic factors for OS but only CERENAL was associated with survival benefit for DSS with a $70 \%$ reduction in risk of death for CERENAL scores lower than 4. Besides, all prognostic scores were also useful during first-line therapy. Multivariate analysis, however, showed that only having a CERENAL score lower than 4 was associated with a $72 \%$ risk of progression compared to patients with a CERENAL score equal to or higher than 4 . This was also clearly depicted in the decision curve analyses for first-line PFS, OS and DSS. It was clearly noted that CERENAL achieved higher net benefits at lower risk thresholds, whereas RTOG RPA was more beneficial at higher risk thresholds. This could indicate that CERENAL could be helpful as a prognostic tool and that the combination with RTOG RPA could lead to the highest net benefit for this patient population. None of the prognostic scores showed significance for second-line therapy.

Our study however has some limitations, especially due to its retrospective nature. Firstly, the presence of brain metastases in RCC is rare. Therefore, the study population is rather heterogeneous and does not allow us to draw hard conclusions. Secondly, due to its retrospective character, it is difficult to 


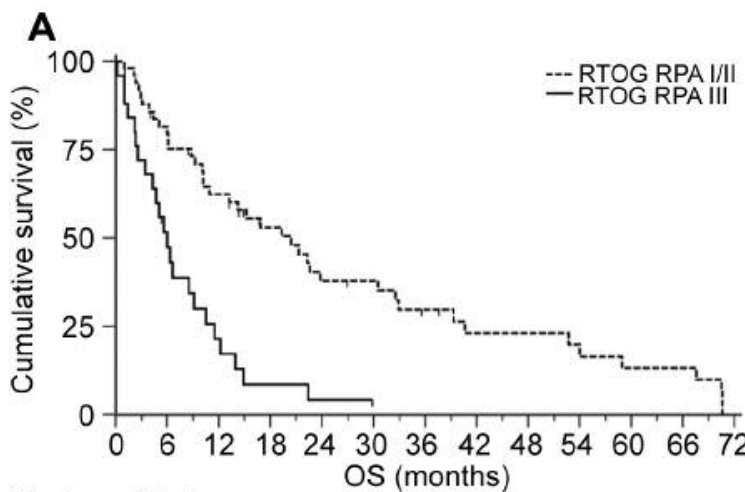

Number at risk

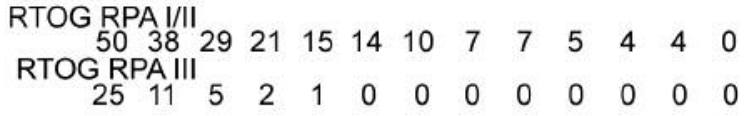

B

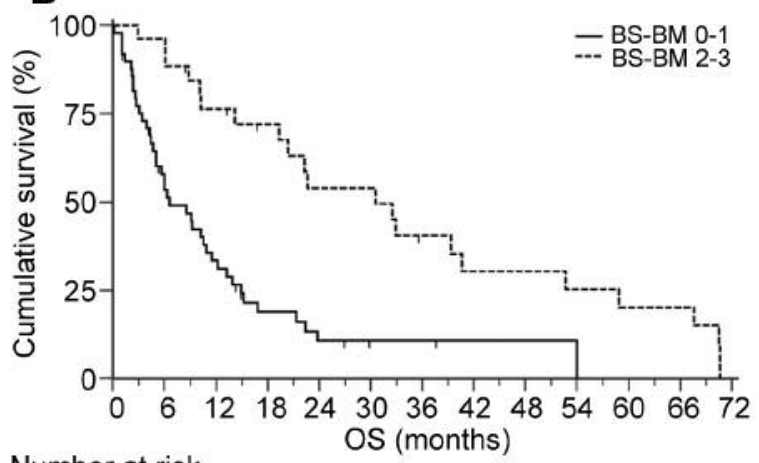

Number at risk

BS-BM 0-1

$\begin{array}{lllllllllllll}49 & 24 & 15 & 7 & 4 & 2 & 2 & 1 & 1 & 0 & 0 & 0 & 0\end{array}$ BS-MB 2-3

$\begin{array}{lllllllllllll}26 & 25 & 19 & 16 & 12 & 12 & 8 & 6 & 6 & 5 & 4 & 4 & 0\end{array}$

C

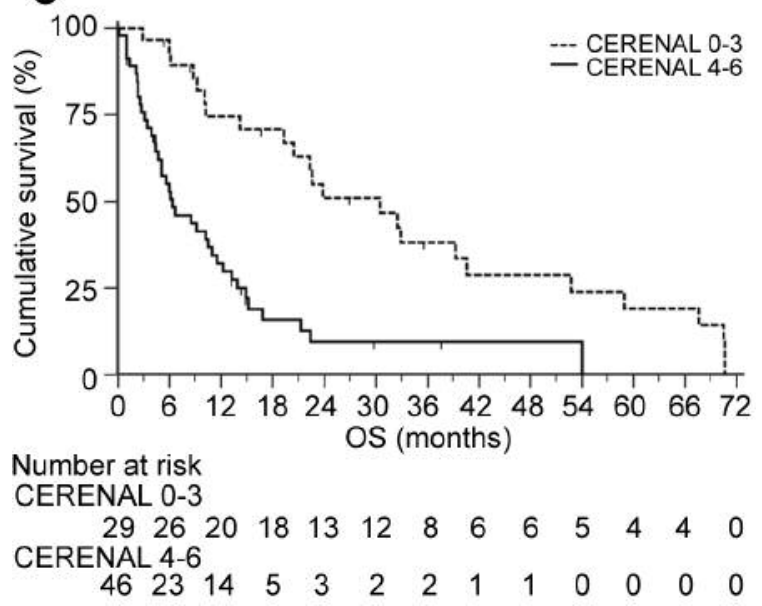

Figure 3. Kaplan-Meier overall survival curves for brain metastasis prognostic scores. Y-axis depicts cumulative survival (\%), X-axis depicts survival time in months. Survival curves are demonstrated for (A) RTOG RPA $(p<0.0001)$, (B) BS-BM $(p<0.0001)$, (C) CERENAL $(p<0.0001)$. BS-BM, Basic score for brain metastases; OS, overall survival; RTOG RPA, radiation therapy oncology group recursive partitioning analysis.

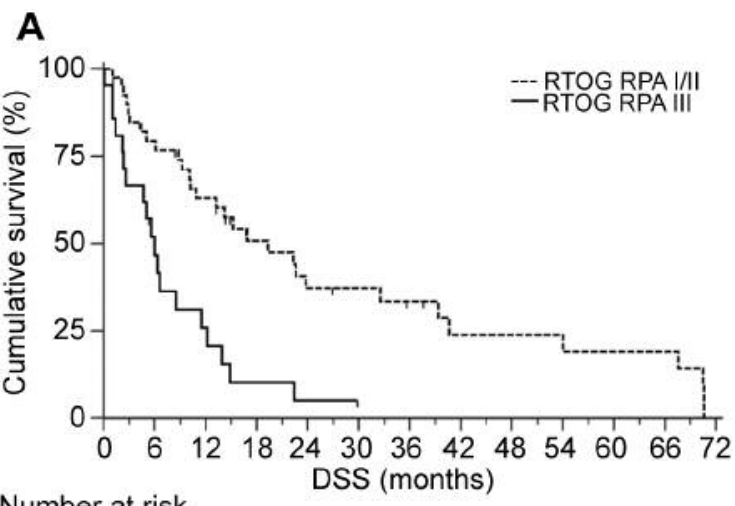

Number at risk

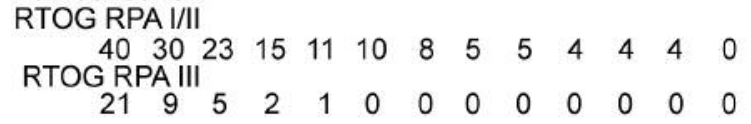

B

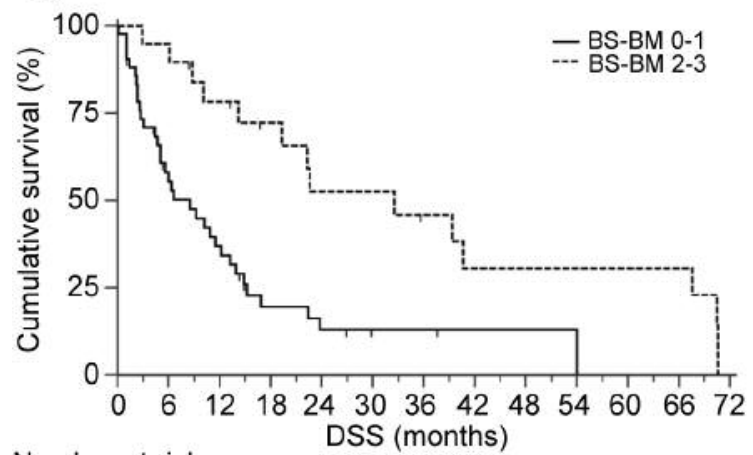

Number at risk

BS-BM 0-1

$\begin{array}{lllllllllllll}42 & 21 & 14 & 6 & 4 & 2 & 2 & 1 & 1 & 0 & 0 & 0 & 0\end{array}$

BS-BM 2-3

$\begin{array}{lllllllllllll}19 & 18 & 14 & 11 & 8 & 8 & 6 & 4 & 4 & 4 & 4 & 4 & 0\end{array}$

C

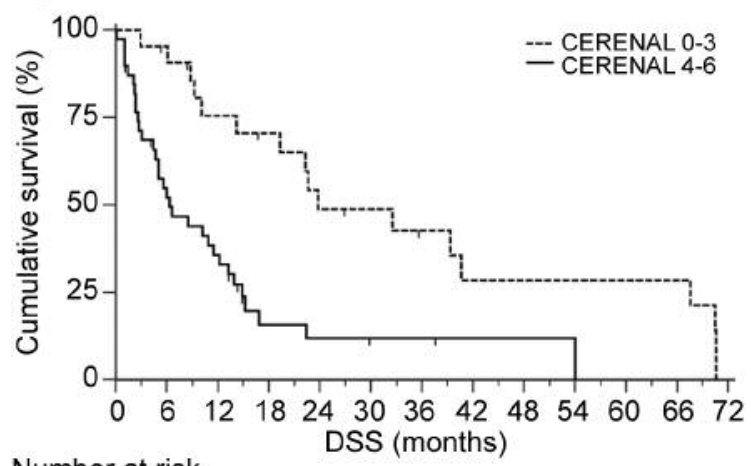

Number at risk

CERENAL 0-3

$\begin{array}{lllllllllllll}22 & 20 & 15 & 13 & 9 & 8 & 6 & 4 & 4 & 4 & 4 & 4 & 0\end{array}$

CERENAL 4-6

$\begin{array}{lllllllllllll}39 & 19 & 13 & 4 & 3 & 2 & 2 & 1 & 1 & 0 & 0 & 0 & 0\end{array}$

Figure 4. Kaplan-Meier disease-specific survival curves for brain metastasis prognostic scores. Y-axis depicts cumulative survival (\%), $X$-axis depicts survival time in months. Survival curves are demonstrated for (A) RTOG RPA ( $p=0.0002)$, (B) BS-BM ( $p=0.0007)$, (C) CERENAL ( $p=0.003)$. BS-BM, Basic score for brain metastases; DSS, diseasespecific survival; RTOG RPA, radiation therapy oncology group recursive partitioning analysis. 
implement decision curve analysis for PFS and OS due to the high number of patients already progressed and deceased, respectively. Thirdly, insufficient data were present in the patient files to determine the prognostic effect of the MSKCC or Heng criteria in our study population. It would be of great interest to determine the added value of the proposed brain metastatic prognostic marker CERENAL value over the already validated prognostic criteria known in RCC. Nevertheless, our retrospective study has shown some interesting findings which can guide future prognostic research in RCC patients diagnosed with brain metastases. Further validation in prospectively enrolled RCC cohorts is, therefore, needed to fully evaluate the prognostic value of the CERENAL score.

\section{Authors' Contributions}

Guarantor of entire study integrity: ZEA; Study concepts and design: ZEA, SR, PB, NK, AA, NP and JBC; Clinical studies/data acquisition: ZEA, SR, PB, NK, RVP, DD, AA, TG, DP, TR, WW, NP and JBC; Experimental studies/data analysis: ZEA, SR, PB, AA, NP and TV; Statistical analysis: ZEA, PB, NP and TV; Literature research: ZEA, PB, NP and TV; Manuscript preparation: ZEA and TV; Manuscript editing: All authors; Final approval of manuscript: All authors.

\section{Conflicts of Interest}

The Authors declare no conflicts of interest with regard to this study.

\section{References}

1 Escudier B, Porta C, Schmidinger M, Rioux-Leclercq N, Bex A, Khoo V, Gruenvald V, Horwich A and ESMO Guidelines Committee. Renal cell carcinoma: ESMO Clinical Practice Guidelines for diagnosis, treatment and follow-up. Ann Oncol 27: v58-v68, 2016. PMID: 27664262. DOI: 10.1093/annonc/ mdw328

2 Ferlay J, Soerjomataram I, Dikshit R, Eser S, Mathers C, Rebelo M, Parkin DM, Forman D and Bray F: Cancer incidence and mortality worldwide: Sources, methods and major patterns in GLOBOCAN 2012. Int J Cancer 136: E359-E386, 2015. PMID: 25220842. DOI: $10.1002 /$ ijc. 29210

3 Moch H, Cubilla AL, Humphrey PA, Reuter VE and Ulbright TM: The 2016 WHO classification of tumours of the urinary system and male genital organs-part A: Renal, penile, and testicular tumours. Eur Urol 70: 93-105, 2016. PMID: 26935559. DOI: 10.1016/j.eururo.2016.02.029

4 Garnick MB: Primary neoplasms of the kidney. In: Brady HR and Wilcox CS, editors. Therapy in nephrology and hypertension: A companion to Brenner and Rector's the kidney. Philadelphia: WB Saunders pp. 337-400, 1998.

5 Heng DY, Xie W, Regan MM, Harshman LC, Bjarnason GA, Vaishampayan UN, Mackenzie M, Wood L, Donskov F, Tan MH, Rha SY, Agarwal N, Kollmannsberger C, Rini BI and Choueiri TK: External validation and comparison with other models of the International Metastatic Renal-Cell Carcinoma Database Consortium prognostic model: a population-based study. Lancet Oncol 14: 141-148, 2013. PMID: 23312463. DOI: 10.1016/ S1470-2045(12)70559-4
6 Gupta K, Miller JD, Li JZ, Russell MW and Charbonneau C: Epidemiologic and socioeconomic burden of metastatic renal cell carcinoma (mRCC): a literature review. Cancer Treat Rev 34: 193205, 2008. PMID: 18313224. DOI: 10.1016/j.ctrv.2007. 12.001

7 Kim WH, Kim DG, Han JH, Paek SH, Chung HT, Park CK, Kim CY, Kim YH, Kim JW and Jung HW: Early significant tumor volume reduction after radiosurgery in brain metastases from renal cell carcinoma results in long-term survival. Int J Radiat Oncol Biol Phys 82: 1749-1755, 2012. PMID: 21640509. DOI: 10.1016/j.ijrobp.2011.03.044

8 Kim YH, Kim JW, Chung HT, Paek SH, Kim DG and Jung HW: Brain metastasis from renal cell carcinoma. Prog Neurol Surg 25: 163-175, 2012. PMID: 22236678. DOI: 10.1159/000331190

9 Sheehan JP, Sun MH, Kondziolka D, Flickinger J and Lunsford LD: Radiosurgery in patients with renal cell carcinoma metastasis to the brain: long-term outcomes and prognostic factors influencing survival and local tumor control. J Neurosurg 98: 342349, 2003. PMID: 12593621. DOI: 10.3171/jns.2003.98. 2.0342

10 Gaspar L, Scott C, Rotman M, Asbell S, Phillips T, Wasserman T, McKenna WG and Byhardt R: Recursive partitioning analysis (RPA) of prognostic factors in three Radiation Therapy Oncology Group (RTOG) brain metastases trials. Int J Radiat Oncol Biol Phys 37: 745-751, 1997. PMID: 9128946. DOI: 10.1016/S03603016(96)00619-0

11 Lorenzoni J, Devriendt D, Massager N, David P, Ruiz S, Vanderlinden B, Van Houtte P, Brotchi $\mathrm{J}$ and Levivier M: Radiosurgery for treatment of brain metastases: estimation of patient eligibility using three stratification systems. Int J Radiat Oncol Biol Phys 60: 218-224, 2004. PMID: 15337559. DOI: 10.1016/j.ijrobp.2004.02.017

12 Weltman E, Salvajoli JV, Brandt RA, de Morais Hanriot R, Prisco FE, Cruz JC, de Oliveira Borges SR and Wajsbrot DB: Radiosurgery for brain metastases: A score index for predicting prognosis. Int J Radiat Oncol Biol Phys 46: 1155-1161, 2000. PMID: 10725626. DOI: 10.1016/S0360-3016(99)00549-0

13 Ferrel EA, Roehrig AT, Kaya EA, Carlson JD, Ling BC, Wagner A, MacKay AR, Call JA, Demakas JJ, Lamoreaux WT, Fairbanks RK, Cooke BS, Peressini B and Lee CM: Retrospective study of metastatic melanoma and renal cell carcinoma to the brain with multivariate analysis of prognostic pre-treatment clinical factors. Int J Mol Sci 17: 400, 2016. PMID: 26999120. DOI: 10.3390/ijms 17030400

14 Vickers AJ, Cronin AM, Elkin EB and Gonen M: Extensions to decision curve analysis, a novel method for evaluating diagnostic tests, prediction models and molecular markers. BMC Med Inform Decis Mak 8: 53, 2008. PMID: 19036144. DOI: 10.1186/14726947-8-53

15 Samlowski WE, Majer M, Boucher KM, Shrieve AF, Dechet C, Jensen RL and Shrieve DC: Multidisciplinary treatment of brain metastases derived from clear cell renal cancer incorporating stereotactic radiosurgery. Cancer 113: 2539-2548, 2008. PMID: 18780316. DOI: $10.1002 /$ cncr.23857

16 Shuch B, La Rochelle JC, Klatte T, Riggs SB, Liu W, Kabbinavar FF, Pantuck AJ and Belldegrun AS: Brain metastasis from renal cell carcinoma: presentation, recurrence, and survival. Cancer 113: 1641-1648, 2008. PMID: 18671240. DOI: 10.1002/ cncr.23769

17 Andrews DW, Scott CB, Sperduto PW, Flanders AE, Gaspar LE, Schell MC, Werner-Wasik M, Demas W, Ryu J, Bahary JP, Souhami L, Rotman M, Mehta MP and Curran WJ Jr:: Whole brain radiation therapy with or without stereotactic radiosurgery boost 
for patients with one to three brain metastases: Phase III results of the RTOG 9508 randomised trial. Lancet 363: 1665-1672, 2004. PMID: 15158627. DOI: 10.1016/S0140-6736(04) 16250-8

18 Aoyama H, Shirato H, Tago M, Nakagawa K, Toyoda T, Hatano K, Kenjyo M, Oya N, Hirota S, Shioura H, Kunieda E, Inomata $\mathrm{T}$, Hayakawa $\mathrm{K}$, Katoh $\mathrm{N}$ and Kobashi G: Stereotactic radiosurgery plus whole-brain radiation therapy $v s$. stereotactic radiosurgery alone for treatment of brain metastases: A randomized controlled trial. JAMA 295: 2483-2491, 2006. PMID: 16757720. DOI: 10.1001/jama.295.21.2483

19 Golden DW, Lamborn KR, McDermott MW, Kunwar S, Wara WM, Nakamura JL and Sneed PK: Prognostic factors and grading systems for overall survival in patients treated with radiosurgery for brain metastases: variation by primary site. J Neurosurg $109 \mathrm{Suppl}$ : 77-86, 2008. PMID: 19123892. DOI: 10.3171/JNS/2008/ $109 / 12 / \mathrm{S} 13$

20 Kocher M, Soffietti R, Abacioglu U, Villa S, Fauchon F, Baumert BG, Fariselli L, Tzuk-Shina T, Kortmann RD, Carrie C, Ben Hassel M, Kouri M, Valeinis E, van den Berge D, Collette S, Collette L and Mueller RP: Adjuvant whole-brain radiotherapy versus observation after radiosurgery or surgical resection of one to three cerebral metastases: results of the EORTC 22952-26001 study. J Clin Oncol 29: 134-141, 2011. PMID: 21041710. DOI: 10.1200/JCO.2010.30.1655

21 Ali MA, Hirshman BR, Wilson B, Schupper AJ, Joshi R, Proudfoot JA, Goetsch SJ, Alksne JF, Ott K, Aiyama H, Nagano O, Carter BS, Chiang V, Serizawa T, Yamamoto M and Chen CC: Improving the prognostic value of disease-specific graded prognostic assessment model for renal cell carcinoma by incorporation of cumulative intracranial tumor volume. World Neurosurg 108: 151156, 2017. PMID: 28754641. DOI: 10.1016/j.wneu.2017.07.109

22 Choueiri TK, Escudier B, Powles T, Tannir NM, Mainwaring PN, Rini BI, Hammers HJ, Donskov F, Roth BJ, Peltola K, Lee JL, Heng DYC, Schmidinger M, Agarwal N, Sternberg CN, McDermott DF, Aftab DT, Hessel C, Scheffold C, Schwab G, Hutson TE, Pal S, Motzer RJ and METEOR investigators: Cabozantinib versus everolimus in advanced renal cell carcinoma (METEOR): final results from a randomised, open-label, phase 3 trial. Lancet Oncol 17: 917-927, 2016. PMID: 27279544. DOI: 10.1016/S1470-2045(16)30107-3

23 Escudier B, Eisen T, Stadler WM, Szczylik C, Oudard S, Staehler M, Negrier S, Chevreau C, Desai AA, Rolland F, Demkow T, Hutson TE, Gore M, Anderson S, Hofilena G, Shan M, Pena C, Lathia C and Bukowski RM: Sorafenib for treatment of renal cell carcinoma: Final efficacy and safety results of the phase III treatment approaches in renal cancer global evaluation trial. J Clin Oncol 27: 3312-3318, 2009. PMID: 19451442. DOI: 10.1200/JCO.2008.19.5511

24 Hutson TE, Escudier B, Esteban E, Bjarnason GA, Lim HY, Pittman KB, Senico P, Niethammer A, Lu DR, Hariharan S and Motzer RJ: Randomized phase III trial of temsirolimus versus sorafenib as second-line therapy after sunitinib in patients with metastatic renal cell carcinoma. J Clin Oncol 32: 760-767, 2014. PMID: 24297950. DOI: 10.1200/JCO.2013.50.3961

25 Motzer RJ, Barrios CH, Kim TM, Falcon S, Cosgriff T, Harker WG, Srimuninnimit V, Pittman K, Sabbatini R, Rha SY, Flaig TW, Page R, Bavbek S, Beck JT, Patel P, Cheung FY, Yadav S, Schiff EM, Wang X, Niolat J, Sellami D, Anak O and Knox JJ: Phase II randomized trial comparing sequential first-line everolimus and second-line sunitinib versus first-line sunitinib and second-line everolimus in patients with metastatic renal cell carcinoma. J Clin Oncol 32: 2765-2772, 2014. PMID: 25049330. DOI: 10.1200/JCO.2013.54.6911

26 Motzer RJ, Escudier B, McDermott DF, George S, Hammers HJ, Srinivas S, Tykodi SS, Sosman JA, Procopio G, Plimack ER, Castellano D, Choueiri TK, Gurney H, Donskov F, Bono P, Wagstaff J, Gauler TC, Ueda T, Tomita Y, Schutz FA, Kollmannsberger C, Larkin J, Ravaud A, Simon JS, Xu LA, Waxman IM, Sharma $\mathrm{P}$ and CheckMate 025 Investigators: Nivolumab versus everolimus in advanced renal-cell carcinoma. N Engl J Med 373: 1803-1813, 2015. PMID: 26406148. DOI: 10.1056/NEJMoa1510665

27 Motzer RJ, Escudier B, Oudard S, Hutson TE, Porta C, Bracarda S, Grünwald V, Thompson JA, Figlin RA, Hollaender N, Kay A, Ravaud A and RECORD-1 Study Group: Phase 3 trial of everolimus for metastatic renal cell carcinoma: Final results and analysis of prognostic factors. Cancer 116: 4256-4265, 2010. PMID: 20549832. DOI: 10.1002/cncr.25219

28 Motzer RJ, Escudier B, Tomczak P, Hutson TE, Michaelson MD, Negrier S, Oudard S, Gore ME, Tarazi J, Hariharan S, Chen C, Rosbrook B, Kim S and Rini BI: Axitinib versus sorafenib as second-line treatment for advanced renal cell carcinoma: overall survival analysis and updated results from a randomised phase 3 trial. Lancet Oncol 14: 552-562, 2013. PMID: 23598172. DOI: 10.1016/S1470-2045(13)70093-7

29 Motzer RJ, Hutson TE, McCann L, Deen K and Choueiri TK: Overall survival in renal-cell carcinoma with pazopanib versus sunitinib. N Engl J Med 370: 1769-1770, 2014. PMID: 24785224. DOI: $10.1056 / \mathrm{NEJMc} 1400731$

30 Sternberg CN, Hawkins RE, Wagstaff J, Salman P, Mardiak J, Barrios CH, Zarba JJ, Gladkov OA, Lee E, Szczylik C, McCann L, Rubin SD, Chen M and Davis ID: A randomised, double-blind phase III study of pazopanib in patients with advanced and/or metastatic renal cell carcinoma: final overall survival results and safety update. Eur J Cancer 49: 1287-1296, 2013. PMID: 23321547. DOI: 10.1016/j.ejca.2012.12.010

31 Kusuda Y, Miyake H, Terakawa T, Furukawa J, Muramaki M and Fujisawa M: Treatment of brain metastases from renal cell carcinoma with sunitinib and radiotherapy: our experience and review of the literature. Int J Urol 18: 326-329, 2011. PMID: 25522450. DOI: 10.1111/j.1442-2042.2010.02706.x

32 Kano H, Morales-Restrepo A, Iyer A, Weiner GM, Mousavi SH, Kirkwood JM, Tarhini AA, Flickinger JC and Lunsford LD: Comparison of prognostic indices in patients who undergo melanoma brain metastasis radiosurgery. J Neurosurg 128: 14-22, 2018. PMID: 28106495. DOI: 10.3171/2016.9.JNS 161011

33 Villa S, Weber DC, Moretones C, Manes A, Combescure C, Jove J, Puyalto $\mathrm{P}$, Cuadras $\mathrm{P}$, Bruna J, Verger E, Balañà $\mathrm{C}$ and Graus F: Validation of the new Graded Prognostic Assessment scale for brain metastases: A multicenter prospective study. Radiat Oncol 6: 23, 2011. PMID: 21366924. DOI: 10.1186/1748-717X-6-23

34 Zindler JD, Rodrigues G, Haasbeek CJ, De Haan PF, Meijer OW, Slotman BJ and Lagerwaard FJ: The clinical utility of prognostic scoring systems in patients with brain metastases treated with radiosurgery. Radiother Oncol 106: 370-374, 2013. PMID: 23522151. DOI: $10.1016 /$ j.radonc.2013.01.015

Received April 8, 2019

Revised April 29, 2019

Accepted April 30, 2019 